\title{
Human Capital, Higher Education Enrolment and Economic Growth in the SSA Countries (Panel Model
} Approach)

\author{
Akinola G. W.*, Bokana K. G. \\ College of Law and Management Studies, University of KwaZulu-Natal, South Africa \\ 214585066@stu.ukzn.ac.za*, bokanakg@ukzn.ac.za
}

\begin{abstract}
This study offers exploratory analysis on the relationship among human capital, higher education enrolment and economic growth in SSA countries. With data from twenty-two African countries across the four economic blocs, five variables which include human capital formation, capital stock, employment rate, total factor productivity and higher education enrolment were regressed against gross domestic product per capital. Panel analysis which includes fixed and random effects analyses were carried out. We report results from fixed effect (within) regression as Hausman test suggests. It was discovered that SADC countries perform better among the four economic blocs. To further study individual country specific effects, we employ least square dummy variables (LSDV). Sixteen countries out of twenty-two exhibit specific effects. Our findings revealed that enrolment rate of higher education in SSA have a very weak relationship with economic growth in the SSA countries. This reflects why there is a weak relationship between economic growth and the total factor productivity and consequently negative consequential effects on our total factor productivity. The main policy implication is that for SSA countries to maintain sustainable economic growth, home based human capital must be given a priority in the form of increased higher education budget and financing.
\end{abstract}

Keywords: Economic growth, Sub Sahara Africa, Human Capital, Higher Education Enrolment

\section{Introduction}

Among the macroeconomic theories, of prominence is the priority placed on the concepts of human capital and sustainable economic growth, this is because these concepts greatly and directly affect the pattern of living of the population and the total wellbeing. From the Sub-Saharan African (SSA) countries experience, according to the World Bank (2008), it is obvious that a nation may have a sustainable growth rate in an economy resulting from physical capital such as equipment, land, raw materials, macroeconomic stability, restructured market imperfection, the removal of trade restriction, integration into global demand and natural resources based products, without having substantive productivity and the ability to sustain it over a giving period of time once the propelling force behind it is not an indigenous human capital (Fleischhauer, 2007). Fitzsimons (1999) argued that human capital acts as a framework for instituting government policies. It is the driver of basic economic activity. Human capital is at the center of any national technological advancement, any productive effort and any meaningful innovation. A nation without trained human capital would be marked with poverty, inequality, low health care, short life expectancy and subsistent livelihood. Developing economy is faced with different economic problems which are directly linked with fluctuations in the major macro-economic variables (Nnanna, Alade, \& Odoko, 2003). The tendency of establishing or finding the correct relationship among the major macro-economic variables such as gross output (GDP), gross capital formation, savings, exchange rate, inflationary rate, employment rate, to mention a few, and their right applications in policy implementation has been the secret of sustainable economic growth of many developed economies which is a reflection of the trained human capital in that economy.

According to Amir, Mehmood, and Shahid (2012), the best choice available for sustainable economic growth is home based human capital. Economic experts are consenting to the fact that it is advancement in productivity that really determine long-run per capital growth rate. Investment in factor input and growth rate in employment can, to a degree of confidence, expand productivity. With efficient allocation of factor input, it is expected that productivity should grow. Investment in education and human capital are the major determinants of productivity growth (Verbic, Majcen, \& Cok, 2009). Having known that human capital is so important, investment into it is germane and will be the secret of prosperity of any nation, and no investible fund spent in the right direction on education will be seen as a wasted effort. Investment in human capital leads to future streams of benefits and real earnings, which positively affects the economy even beyond the initial capital invested. Education is the institution from which human capital is raised.Hassan and Ahmed 
(2008)take a critical look on education from micro concept as giving privileges to individual skills acquisition whereby an individual becomes highly wage competitive; he is given room to stock of knowledge and potentials by which complex and sophisticated task is performed thereby leading to specialization. With education, most recent advancement in technology and productive activities becomes easily adaptable; entrepreneurial skills and mobility of labor is easily carried out in a more advanced ways. Education aids both personal national propensities to save by raising human capital accumulation. In addition, countries' population dependency burden is reduced to minimum level, and builds up an appreciable physical, investment and productive capability.

There is a relationship between economic growth, the level of education and human capital. Between 1980 and 2000, SSA countries witnessed low economic growth and made little progress in raising their levels of education and this low level of education will be evident in the poor performance of human capital formation(Glewwe, Maiga, \& Zheng, 2007). Record from World Bank data estimated that between that same period the Sub-Saharan Africa countries' average growth rate in GDP per capital was $-0.6 \%, 3.6 \%$ for South Asia, in Latin America it was $0.5 \%$, for East Asia it was 4.9\%, Middle East was $1.2 \%$ and, it shows the reasons why SSA countries are economically backward. The nation's population level of educational achievement will steadily reveal and reflect the knowledge, skills, and the level of economic freedom enjoyed. The level of educational attainment that is closely linked with improvement in human capital is the higher education. The role of higher education in development and growth is already drawing a worldwide knowledge-based competitive attention within the economy setting (Bloom, Canning, and Chan, 2006). Higher education in the past was often seen as a highly-priced and unproductive public service that was mostly enjoyed by the wealthy and privileged. In recent time, it has been discovered that higher education necessarily contributes to nation building, especially alongside with other variable inputs to the success of national efforts to boost productivity, competitiveness and economic growth. A critical look from this direction indicates that higher education ceases to compete with primary and secondary education during policy implementation. Instead, to boost innovation and performance across economic sectors, it becomes an essential complement to educational efforts at other levels as well as to national initiatives.

Corazzini, Dugan, and Grabowski (1972) says that it is usually argued that higher education makes available highly skilled human capital that is required to build the advancement in technology of the community and it is expected that the general benefits be increased especially due to abundance of the knowledge provided by the higher education sector. According to Chaudhary, Iqbal, and Gillani (2009), higher education has become crucially significant in an age when intellectual resources and asset is progressively more appreciated and valued, both for individuals and nations,. It can create essential thinkers and innovators as well as strong conversant and engaged society, provides a high standard of living and social mobility, battle with present democratic renewal and health services as well as public policy challenges. Moreover, previously incurable diseases has been battled by the world's higher education institutions and universities through research driven activities, and the fortunes of cities, regions and even nations have been shaped through the provision of facilities for innovative business ideas and political theories. According to Okebukola (2008), for a dynamic economy and enduring speedy societal transformation, higher education provides high level of human capital. It shows that, the more liberal the prospect for rapid social and economic development the greater the opportunity given to the citizenry for higher education. The prospect is in the structure of the higher education participation rate, which according to him is the share of 18-35 years age group that is enrolled in higher education.

When compared with the past, SSA countries witnessed 6\% increase in GDP between 2002 and 2007 as a result of a number of factors including improvement in the macro-economic stability, restructured market imperfection, removal of trade restrictions and integration of natural resources based products into global demand. If SSA countries are to maintain and stimulate this rate of growth, a remarkable improvement of investment in higher education (human capital) and physical capital sustained over a given period of time is indispensable. World Bank (2008) suggested an urgent need for countries in SSA to attain the ladder that will generate latest industries, which will in turn, enhance more productive activities, provide numerous opportunities and more exports promotions, improve managerial and technical expertise in order to maintain the benefits obtained from investment in physical assets such as infrastructure and productive facilities, institutions and human capital.Tilak (2005) argued that enrolment in higher education is relatively small in 
context with the overall secondary school leavers, level skill acquisition is relatively low, and its value is greatly inconsistent. Initial report from World Bank Millennium Development Goal seems not to be favorable to funding of the Sub-Saharan African countries' higher education. This was premised on the reason that the gains and privileges offered by higher education is more of private return than social return to the state at least at the short-run.

Again, primary education was the main argument submitted at The Dakar summit on "Education for All" in 2000 as pivot upon which an expansive social wellbeing of the citizens revolves. The fact that less attention was given to higher education adversely affected the priority given to it during consideration for national policy and this set back suffered by higher education was due to the fact that the empirical evidence on the roles it played in nation building, reduction in poverty and economic growth has not been properly established. Friedman and his wife Rose once argued that higher education can stimulate social disturbances and political insecurity and that there were no convincing facts to show that higher education provides social returns beyond the opportunities enjoyed by the beneficiaries themselves (Tilak, 2005). The unquestionable acceptance of the above has led into relative abandonment of higher education (Bloom et al., 2006), as the bias the international development community has on the preference for more attention on primary and secondary education has attendant negative effects on the low consideration given to higher education by governments of SSA. 17 per cent of the World Bank's global education-sector expenditure was on higher education between 1985 and 1989, compared with 1995 to 1999 when the amount apportioned for higher education reduced to 7 per cent. Despite this reduction, the social expenditure by the SSA government also reduced, to even sustain the existing low levels of enrolment became difficult as was evidenced in the academic research output in the region being among the lowest across the globe.

It is amazing that SSA countries accounting for more than 11 per cent of the population of the world (720 million) could have only 3 per cent (4.5million) of the student number in higher education. The gross enrolment ratio was barely 6 per cent as against 70 per cent in the high income countries of the World. From the 4.5 million, Nigeria has 1.5 million and South Africa 0.7 million. In several nations, such as Tanzania, Chad, Malawi, Central African Republic and Niger, the enrolment in higher education ranges between 2 percent or even lower in 2010 (Bloom et al., 2014). Some countries like Congo, Angola and Somalia seems to have a decline in their university-level institutions over the years (Tilak, 2011). Again, in contrast to the earlier view of argument against higher education on government funding, some of the outcome of recent research revealed that higher education is a determining factor as well as the engine to economic growth. This is because it can boost national productivity and can generate private and public benefits. Higher education has the potentials of increasing savings and investment, and builds up tax revenue for government, thereby leading to a society with more entrepreneurial skills. It can proffer solution to the problem of population growth in the region, develop home based technology, improve a countries' health, and promote good governance.

When measuring some of the advantages attributed to the benefits coming from higher education for a country's economy, many researchers attributed India's giant breakthrough into the global economic arena as a product of her decades of long thriving hard work to promote super technically endowed higher education to a considerable number of her populace (Bloom et al, 2006). The extent of the priority of higher education to countries' growth in the economy as it affects SSA countries has not been significantly and empirically verified. The outcome of findings across literatures on the relationship among human capital, economic growth and the level of higher education enrolment are quite mixed. While some have positive relationship, some are found to have negative relationship. Examples of such are Nurudeen \& Usman, (2010) and Belgrave \& Craigwell (1995), whose empirical findings showed that there is a negative impact that higher education human capital has on economic growth. To the peculiarities of individual countries in the SSA, this mixed empirical evidence is more chronic requiring further investigation. Some literatures approach such relationship without empirical analysis (Tilak, 2011), while others used divers variables which may not really hit the nails on the head; few of such researchers include Adawo, (2011); Bergh \& Fink, (2008); Sojkin, Bartkowiak, \& Skuza, (2012); Barro (1996); Chowdry, Crawford, Dearden, Goodman, \& Vignoles, (2008); Tilak, (2011). Bloom et al. (2006) acknowledged the peculiarities of Sub-Saharan Africa and advocates further research. 
In recent years, attention of most monetary organizations such as the World Bank, International Monetary Fund and other governmental aid supporters seems to be shifting away from the exclusive priority giving to primary education and are beginning to show concern to secondary and higher education, striking a balance among the three levels of education and their roles in growth promotion and reduction of poverty, which brings some rays of hope to higher education in SSA. The fact that some countries of the SSA are now putting policies in place to encourage higher education systems is worthy of our commendation. But when compared with the achievement made so far with other regions across the globe, the efforts here are still negligible. This low effort is a product of low knowledge of the significant positive effect that higher education has on the SSA economy. These policies in each country need not to be subjective but rather empirically supported as this will heighten their sense of commitment as hitting the ball on a target goalpost. The purpose of this research work is to empirically establish that human capital through higher education enrolment in SSA is one of the important determining conditions for individual country's economic growth. This study seeks to determine the relationship among human capital, higher education enrolment and economic growth in the various economic blocs of the SSA countries. We shall achieve this as we determine the relationship between human capital, higher education enrolment and economic growth in the various economic blocs of the SSA countries as well as evaluate the possible spill-over effect resulting from the relationship between human capital, higher education enrolment and economic growth in the various economic blocs of the SSA countries.

The dynamic nature of the world economy is sending red alert as it is creating wider gap to SSA economy which calls for urgent attention. The gap cannot be unconnected with shortage in the required human capital available in sufficient quantity as to commensurate with the demand for productivity, competitive labor market in SSA countries. The major problem confronting SSA countries is the low enrolment rate in higher education (which remains the lowest in all regions of the world) and this low enrolment rate is visible in the low human capital available in its economies. The role of higher education as a link between human capital, the labor market and the economy has been empirically verified in literature. The right application of this empirical evidence is a reflection of progress witnessed in the developed nations of the world. The marginal gap between the developed nations and the developing economy of the SSA countries is an indication that the outcome of the empirical findings which has been used for the developed nations needed to be developed, and probably modified also, to suit the SSA economies. Going by the current population growth rate in the region, we hypothesized that what percentage of student enrolment would ensure human capital that would measure up to the required challenge in the economy of the region? This question is of great importance to the success of this study. The objective of this study is to analyze the impact of higher education human capital on the economic growth of the SSA countries.

\section{Human Capital, Higher Education Enrolment and Economic Growth Relationship}

Endogenous growth theory originated from Lucas (1988) and Romer (1986), and argues that the absorption of new accumulation of innovation and knowledge will generate self-induced growth in the economy, causing growth patterns to be divergent. The growth theory postulates that, for positive long run sustenance of the growth rate per capita to be achieved, consistent new processes and advancement in technological knowledge is required. If technological progress halts, diminishing returns set in. This causes economic growth to cease (Aghion, Howitt, Brant-Collett, \& García-Peñalosa, 1998; Lucas, 1988). This proposition has drawn the attention of scholars across the field of economics, which gave birth to endogenous growth theory. For instance, while adopting the Cobb Douglas production function, in his model, Mankiw et al. (1992) argued that the neoclassical model is sufficient to account for differences across countries' economic growth paths, if an expansive view of capital which takes physical and human capital into account is adopted. However, since it takes technological progress which is a fundamental determinant of the growth process as exogenous, (Aghion et al., 1998) argued that the model lacks the capacity to account for the persistent growth rate of each country. Although many factors have been identified that determine economic growth, human capital is fundamentally unique (Barro, 1996; Mankiw et al., 1992; Hanushek \& Kimko, 2000). The importance and uniqueness of human capital as a growth factor is premised on the fact that, its skills determine growth in productivity(Verbic et al., 2009). Again, among those factors that determine human capital, education is germane (Glewwe, Maiga, and Zheng, 2007; Hassan and Ahmed (2008). There are diverse views on which education sector has the greatest impact on human capital. While Okebukola (2008), Corazzini et al. (1972), and Chaudhary et al. (2009) argued that higher education creates the highly skilled human capital that is 
required to build advancement in technology, Anyanwu \& Erhijakpor, (2007) cited primary and secondary education as the major determinants of human capital. Among the proponents of higher education as the determinant of human capital, there is generally no acceptable measure of such capital. While Zivengwa (2006); Barro (2001) and Mankiw et al. (1992), among others, used the enrolment rate as a proxy for human capital, they failed to account for dropout rates. Researchers such as (de La Fuente,\&Domenech 2011) and(Barro \& Lee, 1993)used school attainment while the $H=e^{\eta(s)}$ in Mincer's macro equation represents human capital where (s) represents year of schooling. This leads us to empirical works by scholars on this concept.

The growth accounting method was used by Matsuschita et al. (2006) to consider the impact of education to growth in Australia over the period 1969-2003. The study also regressed on the impact of total factor productivity to growth. It was discovered that per capita real GDP in Australia was raised by 1.9 percent annually, from which about 31 percent was impacted by education. The outcome of the finding has significant implications for Australia's policy makers. For example, access to post compulsory education is a function of promoting economic growth in the years ahead, Australia's vocational training, education and higher education becomes cheaper and easier. This finding is opposed to extant trend of government policy towards increasing the student share of the cost on education. Chaudhary et al. (2009) used Johansen co-integration causality approach in Vector Autoregressive (VAR) framework to estimate the long-run contribution of higher education on the economic growth Pakistan. The result confirmed that there is a long-run relationship existing between higher education and economic growth in Pakistan. The result confirmed that that there is a unidirectional causality running from economic growth to higher education and no other direction of causality was discovered among the variables. Anyanwu and Erhijakpor (2007) used panel data analysis to estimate the contribution of government expenditure on education enrolment from four African SANE countries. SANE here represents Algeria, South Africa, Egypt and Nigeria. The research work centred basically on primary and secondary education and the results showed that government expenditure on education impact positively on both primary and secondary enrolment with Nigeria recording the greatest impact. Democracy index and urban population were included as these variables were found to have direct impact on both education spending and education capital. The work also suggested that policy intervention program which will enhance a sustained democracy and other international aid support program will be required for African countries to attain the millennium development goals. Olawumi Ogungbenle and Obasuyi (2013), making use of OLS and annual time series data from 1977 to 2007, examined social spending on education and health as catalysts to economic growth in Nigeria. It was found out that both variables impact positively on economic growth. However, the impact of education appears to be stronger than that of health on economic growth. It was therefore recommended that health and education should be priories to optimize national growth.

\section{Methodology}

Model Specification: We augment Cobb Douglas' production function for labour input effectiveness, where labour force combines with level of human capital (Bloom et al, 2014; Holland, Liadze, Rienzo, \& Wilkinson (2013).

$Y_{i t}=A_{i t} K^{\alpha}{ }_{i t}\left(L_{i t} V_{i t}\right)^{\beta}$

where

$Y_{i t}=$ Total output in country $i$ at time $t$.

$A_{i t}=$ TFP in country $i$ at time $t$.

$K_{i t}=$ Physical capital in country $i$ at time $t$.

$L_{i t}=$ Labour force in country $i$ at time $t$.

$V_{i t}=$ Level of human capital per worker in country $i$ at time $t$.

$\left(L_{i t} V_{i t}\right)=$ Labour input effectiveness

$\alpha$ and $\beta=$ partial elasticity coefficient of output with respect to physical and human capital in country $i$ at time $t$. 
To disaggregating $V_{i t}$ into:

$V_{i t}=\left(N_{i t} G_{i t}\right)$

The multiplicative function is consistent with the work of Holland et al. (2013); Adawo (2011) and Mankiw et al. (1992) where labour is disaggregated into various types of labours in its multiplicative form and we include higher education enrolment, and higher education output to control for dropout rate. Again, higher education enrolment, initial level of education and level of school attainment is used to proxy human capital (Zivenqwa, 2012; Barro, 2001).

Where

$N_{i t}=$ Enrolment in higher education in country $i$ at time $t$.

$G_{i t}=$ Output from higher education in country $i$ at time $t$.

$Y_{i t}=A_{i t} K^{\alpha}{ }_{i t}\left(L_{i t} N_{i t} G_{i t}\right)^{\beta}$

To take the log of Equation (3.3)

$\log Y_{i t}=\log A_{i t}+\alpha \log K_{i t}+\beta\left(\log L_{i t}+\log N_{i t}+\log G_{i t}\right)$

In summary, the production function aggregate when linearised can be expressed thus:

$$
\log Y_{i t}=\log A_{i t}+\alpha \log K_{i t}+\beta \log L_{i t}+\beta \log N_{i t}+\beta \log G_{i t}
$$

We introduce $\varepsilon_{i t}$,to capture the unexplained phenomenon(random shock) which was not captured in the adjustment process.

$Y_{i t}=\log A_{i t}+\alpha \log K_{i t}+\left(\beta \log L_{i t}+\beta \log N_{i t}+\beta \log G_{i t}\right)+\varepsilon_{i t}$

The $y_{i t}, k_{i t}, l_{i t}, n_{i t}, g_{i t}$ are the logs of $Y_{i t}, K_{i t}, L_{i t}, N_{i t}, G_{i t}$, respectively.

The equation reveals that output depends on enrolment in higher education, higher education output, labour and stock of capital.

For output $\left(y_{i t}\right)$,we use the logged difference of per capita GDP at constant 2005 national prices as the dependent variable for country $i$ in period $t$ to ensure the growth rate.

Capital stock $\left(k_{i t}\right)$ at current PPPs (in millions 200US\$) is used as proxy for physical capital. For labour force $\left(l_{i t}\right)$, employment rate is used to capture the number of persons engaged (in millions),enrolment rates shall proxy higher education enrolment $\left(n_{i t}\right)$, completion rate shall higher education output $\left(g_{i t}\right)$ for country $i$ in period $t$.TFP $\left(a_{i t}\right)$ for country $i$ in period $t$ is supplied in our data, $\left(\varepsilon_{i t}\right)$ denotes the error term while $\alpha$ and $\beta$ are coefficients of estimation. Our expectation from a priori theory in production function is that $a_{i t}, k_{i t}, l_{i t}, n_{i t}$ $g_{i t}$, must be positively signed (Mankiw et al., 1992; Anyanwu and Erhijakpor, 2007).

Data Sources: We employed data for Sub-Saharan African countries covering the period 1980-2013. Most secondary data required for this study are readily available and were sourced from the World Development Indicators database of the World Bank and Penn world Table 8.0.We are constraints to adopt data from 1980 to 2013 because of the choices of our model and to control for omitted variables.

Justification for the Methodology Adopted: Clarke et al. (2010) argue that the action of Fixed and random effects models is done to eliminate biasness of omitted variable as it quantifies changes within group. The within group measurement (across time) control for a number of potential omitted variables peculiar to groups. Inference is the key issue differentiating Fixed Effects from Random Effects. Since fixed-effects estimator could only control for inferences about the group of measurements. On the other hand a randomeffects estimator permits inferences on issues about the population upon which sample is drawn. If there is large enough size effect on the concept relative to the variance between the chosen concepts, one can be 
assured that sampled population would exhibits that effect. Premise upon this argument, we have chosen fixed and random effects estimator to investigate the human capital education variable and the corresponding effects on SSA economic growth. We are constraints to limit our analysis to panel approach static modal as the result is sufficient to justify our expectation in some sense while problem on endogeneity is remains unaccounted for in this study.

\section{Results}

In this section, the data from twenty-two countries containing all the expected variables have been pooled together. Panel analysis which includes fixed and random effects analysis had been conducted in this section. This is done to allow the analysis emerge with the estimate that is both consistent and efficient. Diagnostic test on Hausman test was carried out to know which of the fixed or random effects is preferred for the study in other to verify the existence of serial correlation, the test on autocorrelation was performed. We begin the analysis of panel models which comprise of both the fixed and random effects with the estimation and interpretation of the analysis, while Tables 3 and 4 contain the estimated fixed effect within regression and random effects regression results respectively.

Table 1: Descriptive Statistics

\begin{tabular}{llllll}
\hline Variable & Obs & Mean & Std. Dev. & Min & Max \\
\hline Gdpna & 748 & 24372.99 & 57999.86 & 1051.9 & 399522.6 \\
Emp & 748 & 4.072266 & 4.515062 & .1768752 & 22.09982 \\
Pck & 748 & 51514.77 & 127119.2 & 954.1815 & 978322 \\
Hee & 748 & 187.381 & 4993.468 & .01068 & 136574 \\
Ctfp & 748 & .3973829 & .2882075 & .0731556 & 3.071847 \\
humcap & 748 & 1.801425 & .4568992 & 1.090541 & 6.682602 \\
\hline
\end{tabular}

Source: Author's Computation

Summary Statistics Results: Table 1 reports the baseline results of the summary of statistics which explains the data distribution in terms of its mean and variance. The result shows that some variables clustered around the minimum. For instance, the mean value of employment (labor) is 4.072266 which is nearer the minimum value 0.1768752 than the maximum 22.09982; the mean value of capital stock is 51514.77 which is nearer the minimum value 954.1815 than the maximum 978322, the mean value of higher education enrolment is 187.381 which is nearer the minimum value 0.01068 than the maximum 136574 ; the mean value of total factor productivity is 0.3973829 which is nearer the minimum value 0.0731556 than the maximum 3.071847; the mean value of human capital is 0.3973829 which is nearer the minimum value 1.090541 than the maximum 6.682602.Again, high level of variance is noted in variables such as Gdpna (57999.86), capital stock (127119.2), and higher education enrolment (4993.468). However, some variables exhibited low variance, i.e. employment (labor) having $4.515062,0.2882075$ for total factor productivity and human capital with 0.4568992 respectively.

Correlation Matrix: The correlation matrix is computed for all the variables in other to investigate the expected relationship among the variables

Table2: Results of the correlation matrix

\begin{tabular}{lllllll}
\hline & Gdpna & Emp & Pck & Hee & ctfp & Humcap \\
\hline Gdpna & 1.0000 & & & & & \\
Emp & 0.5911 & 1.0000 & & & & \\
Pck & 0.9821 & 0.5842 & 1.0000 & & & \\
Hee & 0.0001 & 0.0292 & -0.0030 & 1.0000 & & \\
Ctfp & 0.2252 & -0.1311 & 0.1385 & -0.0037 & 1.0000 & \\
humcap & 0.3584 & 0.1013 & 0.3473 & 0.0031 & 0.3666 & 1.0000 \\
\hline
\end{tabular}

Source: Author's Computation

Table 2 presents correlation relationships existing among dependent variable (economic growth) and the independent variables. There is a positive relationship between economic growth and employment (labor), 
having 0.5911. For capital stock and economic growth, apart from having positive relationship, its value of 0.9821 exhibits a very high positive relationship. However, higher education enrolment though showed positive relationship with gdpna but the coefficient is extremely low. It is again very clear that there is a weak relationship between economic growth and the total factor productivity because the correlation coefficient as shown is 0.2252 .The human capital of the value 0.3584 is also very weak though it exhibits positive relationship with the economic growth. The fact that negative relationship is found between higher education enrolment and total factor productivity $(-0.0037)$ is a clear indication that higher education enrolment has an issue especially with 0.0031 figure showing a very weak relationship with human capital. The fixed effects regression results revealed that all the independent variables; employment (labor), capital stock, total factor productivity and human capital are statistically significant except higher education enrolment which is not significant having the value of 0.171.0ur result partially support the findings of Shaihani et al. (2011); Gemmell (1996) and Mchahon (1998) who established a negative relationship between higher education and economic growth.

Table 3: Fixed Effects (within variation regression) Estimation Results

\begin{tabular}{lllllll}
\hline Lgdpna & Coef. & Std. Err. & $\mathbf{t}$ & \multicolumn{2}{c}{$\mathbf{P}>|\mathbf{t}|$} & \multicolumn{2}{c}{ [95\% Conf. Interval] } \\
\hline Lemp & 1554.884 & 88.08726 & 17.65 & 0.000 & 1381.946 & 1727.822 \\
Lpck & .3202225 & .0032175 & 99.53 & 0.000 & .3139058 & .3265393 \\
Lhee & .0288579 & .0210741 & 1.37 & 0.171 & -.012516 & .0702319 \\
Lctfp & 5621.193 & 655.7883 & 8.57 & 0.000 & 4333.71 & 6908.676 \\
lhumcap & -2772.275 & 469.3435 & -5.91 & 0.000 & -3693.718 & -1850.832 \\
_cons & 4299.771 & 876.7875 & 4.90 & 0.000 & 2578.41 & 6021.133
\end{tabular}

Wald chi2 (8) = 19894.22; Prob > chi2 = 0.0000; R-sq: within $=0.9659$

Number of obs $=748$; Number of groups $=22$

${ }^{*}$ statistical significance at $10 \%{ }^{* *}$ statistical significance at $5 \%{ }^{* * *}$ statistical significance at $1 \%$

Table 4: Random Effects Estimation Results

\begin{tabular}{lllllll}
\hline Lgdpna & Coef. & Std. Err. & $\mathbf{z}$ & $\mathbf{P}>|\mathbf{z}|$ & \multicolumn{2}{c}{ [95\% Conf. Interval] } \\
\hline Lemp & 1537.138 & 90.57259 & 16.97 & 0.000 & 1359.619 & 1714.657 \\
Lpck & .3238298 & .00329 & 98.43 & 0.000 & .3173815 & .330278 \\
Lhee & .029248 & .0218452 & 1.34 & 0.181 & -.0135678 & .0720638 \\
Lctfp & 5994.105 & 675.9716 & 8.87 & 0.000 & 4669.225 & 7318.985 \\
lhumcap & -2735.072 & 483.0248 & -5.66 & 0.000 & -3681.783 & -1788.36 \\
Decc & 11563.12 & 7300.934 & 1.58 & 0.113 & -2746.445 & 25872.69 \\
Deco & 8397.326 & 6882.603 & 1.22 & 0.222 & -5092.327 & 21886.98 \\
Dsad & 20081 & 6551.951 & 3.06 & 0.002 & 7239.41 & 32922.59 \\
_cons & -9549.364 & 6031.627 & -1.58 & 0.113 & -21371.14 & 2272.408 \\
\hline
\end{tabular}

Wald chi2(8) = 19894.22; Prob> chi2 $=0.0000$; Number of obs = 748; R-sq: within $=0.9658$

Number of groups $=22$

* Statistical significance at $10 \%{ }^{* *}$ statistical significance at $5 \%{ }^{* * *}$ statistical significance at $1 \%$

Source: Author's Computation

It is again shown that only employment (labor) and total factor productivity with coefficient values 1554.884 and 5621.193 respectively show a very high and positive relationship with economic growth, while capital stock and higher education enrolment though show positive relationship with economic growth with coefficient values 0.3202225 and 0.0288579 respectively, but the value of the figures revealed there is a very weak relationship it shows a strong contribution to growth among the SSA countries. It indicates that the productive unit of the economies namely none education section such as primary and secondary sector impact more growth. Higher education enrolment on the other hand does not impact on growth. The result is puzzling, but shows that higher education which absorbed only about $7 \%$ of the enrollable members of the society has not been adequately supported among the SSA countries and hence requires urgent policy intervention (Bloom et al., 2014).There is a negative relationship between economic growth and human capital with the coefficient value of -2772.275 . This negative relationship cannot be unconnected with the insignificant nature of higher education enrolment contribution to economic growth. The high coefficient value of total factor productivity cannot be unconnected with positive relationship of employment(labor) and 
its contribution to economic growth. From the random effects result, the insignificant value of higher education enrolment which is 0.181 further corroborates the results from fixed effects. In addition, the result from the four economic blocs of the SSA countries shows that only SADC countries having 0.002 value is statistically significant. Despite the similarities in the estimated results from the two panel models, yet there are slight differences. Therefore, the next analysis is to test which of the two models is more appropriate for our analysis. This is done through the Hausman test. The result of the Hausman test is presented in table 5.

Table 5: Hausman test for Panel Models

\begin{tabular}{lllll}
\multicolumn{1}{c}{ Fixed } & $\begin{array}{l}\text { (b) } \\
\text { fixed }\end{array}$ & $\begin{array}{l}\text { (B) } \\
\text { random }\end{array}$ & $\begin{array}{l}\text { (b-B) } \\
\text { Difference }\end{array}$ & $\begin{array}{l}\text { sqrt(diag(V_b-V_B)) } \\
\text { S.E. }\end{array}$ \\
\hline Lemp & 1554.884 & 1537.138 & 17.74533 & 11.62019 \\
Lpck & .3202225 & .3238298 & -.0036072 & .0005484 \\
Lhee & .0288579 & .029248 & -.0003901 & .0002202 \\
Lctfp & 5621.193 & 5994.105 & -372.9117 & 72.21254 \\
Lhumcap & -2772.275 & -2735.072 & -37.203 & 58.38994 \\
chi2 $(0)=(b-B) '\left[\left(V_{-} b-V_{-} B\right)^{\wedge}(-1)\right](b-B)=44.55 ;$ Prob $>$ chi2 $=0.0000$ & \\
\hline
\end{tabular}

Test: Ho: difference in coefficients not systematic

Table 6: Fixed Effects (LSDV) Estimation Results

\begin{tabular}{lllllll}
\hline Lgdpna & Coef. & Std. Err. & $\mathbf{t}$ & $\mathbf{P}>|\mathbf{t}|$ & \multicolumn{2}{l}{ [95\% Conf. Interval] } \\
\hline Lemp & 1554.884 & 88.08726 & 17.65 & 0.000 & 1381.946 & 1727.822 \\
Lpck & .3202225 & .0032175 & 99.53 & 0.000 & .3139058 & .3265393 \\
Lhee & .0288579 & .0210741 & 1.37 & 0.171 & -.012516 & .0702319 \\
Lctfp & 5621.193 & 655.7883 & 8.57 & 0.000 & 4333.71 & 6908.676 \\
Lhumcap & -2772.275 & 469.3435 & -5.91 & 0.000 & -3693.718 & -1850.832 \\
Country & & & & & & \\
2 & 4586.525 & 759.6266 & 6.04 & 0.000 & 3095.181 & 6077.869 \\
3 & 433.2637 & 712.4477 & 0.61 & 0.543 & -965.4562 & 1831.984 \\
4 & 5272.787 & 1050.775 & 5.02 & 0.000 & 3209.843 & 7335.732 \\
5 & 994.5587 & 705.9458 & 1.41 & 0.159 & -391.3961 & 2380.514 \\
6 & 2784.016 & 734.7787 & 3.79 & 0.000 & 1341.454 & 4226.577 \\
7 & -6115.453 & 695.1196 & -8.80 & 0.000 & -7480.154 & -4750.753 \\
8 & -4141.354 & 737.4504 & -5.62 & 0.000 & -5589.16 & -2693.547 \\
9 & 889.6746 & 721.5112 & 1.23 & 0.218 & -526.8393 & 2306.188 \\
10 & 1735.134 & 731.1354 & 2.37 & 0.018 & 299.7251 & 3170.542 \\
11 & -7409.434 & 847.2949 & -8.74 & 0.000 & -9072.894 & -5745.974 \\
12 & 1590.912 & 751.5732 & 2.12 & 0.035 & 115.3785 & 3066.445 \\
13 & 1669.66 & 028.523 & 1.62 & 0.105 & -349.5972 & 13688.917 \\
14 & 3292.731 & 824.738 & 3.99 & 0.000 & 1673.556 & 4911.905 \\
15 & 3369.168 & 881.5651 & 3.82 & 0.000 & 1638.426 & 5099.909 \\
16 & 1758.205 & 697.3239 & 2.52 & 0.012 & 389.1772 & 3127.233 \\
17 & 2291.637 & 921.4857 & 2.49 & 0.013 & 482.5216 & 4100.753 \\
18 & 67720.98 & 1773.465 & 38.19 & 0.000 & 64239.21 & 71202.75 \\
19 & 35846.84 & 982.2843 & 36.49 & 0.000 & 33918.36 & 37775.32 \\
20 & 2910.099 & 1049.345 & 2.77 & 0.006 & 849.9617 & 4970.236 \\
21 & -1480.825 & 895.9308 & -1.65 & 0.099 & -3239.77 & 278.12 \\
22 & -16620.08 & 1128.168 & -14.73 & 0.000 & -18834.96 & -14405.19 \\
cons & -308.3671 & 787.5291 & -0.39 & 0.695 & -1854.491 & 1237.757 \\
R-squared $=0.9750=($ overall) & $\mathrm{F}(5,742)=5776.21 ;$ Prob> F $=0.0000$ & & \\
Number of obs $=748$ & & & & & \\
\hline
\end{tabular}

Note: Standard error in parenthesis

** Statistical significance at $5 \%$. $^{* *}$ * statistical significance at $1 \%$.

Source: Authors Computation 
The results from the hausman test suggest we accept the alternative hypothesis and reject the null hypothesis. The implication of this is that we accept the results from the fixed effect and reject random effects results. Therefore fixed effect result is more suitable for our analysis. Hence, the few places where we noticed slight differences in the results of the model means we stick with the outcomes of the fixed effect in those areas.

Cross-sectional dependence test using fixed effect Least Square Dummy Variable (LSDV): As earlier stated in the introductory aspect of this research that a host of diagnostic tests will be conducted this includes inter alia the test for cross sectional dependence. This is the next test to be explored here. The reason for this is to test whether specific characteristics of individual country can interfere with our panel results. This is necessary as it will enable us determine if we can generalize our results for all the twenty-two countries used in the study. This test is done through fixed effect estimation special case called fixed effect least square dummy variable LSDV. The results of the fixed effects LSDV is presented in table. The LSDV result is an extension of the fixed effects results. The test computes coefficient for dummy variables as intercept or constant for all the twenty-two countries. It also tests their individual statistical significance. It should be noted that the first aspect of the result is just a repetition of the fixed effects within regression we did earlier and which appeared in table 3. The remaining coefficients are the constants which represents dummy variable for each country. The LSDV result shows that out of the twenty-two countries investigated in our study sixteen out of twenty-two have their constants to be statistically significant. The implication of this is that the cross-sectional dependence noticed may be more pronounced in these sixteen countries as it appears they share common features but the degree of the common features varies across countries. This is an important area for further research. This might involve studying of the countries individually to know those countries with specific characteristics that distinguish them from others.

\section{Discussion and Conclusion}

The result of the panel model under correlation matrix suggest that enrolment rate of higher education in SSA has a very weak relationship with economic growth in the SSA countries. Under this model, higher education enrolment though showed positive relationship, it is however very weak (0.0001).This seems to support the findings of Adawo (2011) that tertiary education dampens economic growth. The correlation coefficient table shows that there exist a very strong relationship up to the value of 0.9821 between the capital stock in the region and GDP. It is again noted that the total factor productivity and human capital having the values of 0.2252 and 0.3584 respectively exhibit a very weak relationship with GDP. This is seen to be in contrast with the study carried out on synovia by Verbic et al. (2009) who found economic growth to be endogenously determined in the model by the development of human capital stock as well as the development over time of the overall total factor productivity. Furthermore, the table further showed a negative $(-0.0037)$ relationship between higher education enrolment and total factor productivity and consequently a weak relationship (0.0031) was seen to exist between human capital and higher education enrolment.

The Table3 under fixed effect (within) regression shows that all the independent variables are seen to reflect and to be significant at 5\% level of significance except higher education enrolment with the value of 0.171 shows insignificance as well share a very weak coefficient of 0.0288579 and 0.3202225 with capital stock as against GDP. Again, it was further found that human capital having a negative coefficient of -2772.275 is negatively related with GDP. This again contradicts Hassan and Ahmed(2008) who found a positive correlation between growth and human capital in the SSA countries. This weakness cannot be unconnected with the effect of the insignificant nature of higher education enrolment in the region. This is in conflict with the Romer (1986) argument that endogenous growth theory which emphasize that broad categories of investment activities, such as acquisition of knowledge and human capital, were not subject to diminishing returns because they generated productivity spillovers to the rest of the economy (Romer, 1986). However, with 5621.193 value of total factor productivity, our results show there is a very strong relationship between TFP and the GDP which could be caused by various factor variables. Our results have clearly shown that human capital has not been adequately developed and supported among the SSA countries and unfortunately the part to this human capital improvement which is the expansion of the higher education sector is again not doing well to impact on economic growth at all. The main policy implications for the SSA countries among others are that they have to undertake radical and urgent transformation policy that will turn the tunnel of 
low higher education enrolment in the region. To achieve this vital goal of expansion of higher education and sustainable economic growth, home based human capital must be supported and given a priority in the form of increased higher education budget and financing. In conclusion, higher education human capital does generate productivity spillovers to the rest of the economy.

\section{References}

Adawo, M. A. (2011). Has education (human capital) contributed to economic growth of Nigeria. Journal of economic and international finance, 3(1), 46-58

Aghion, P., Howitt, P., Brant-Collett, M. \& García-Peñalosa, C. (1998). Endogenous growth theory: MIT press.

Amir, M., Muhamood, B. \& Shahid, M. (2012). Impact of human capital on economic growth with emphasis on intermediary role of technology: Time series evidence from Pakistan. African journal of Business Management, 6(1), 280-285.

Anyanwu, J. C. \& Erhijakpor, A. E. O. (2007). Education Expenditures and School Enrolment in Africa: Illustrations from Nigeria and Other SANE Countries: African development bank, 1-11.

Barro, R. J. (1996a), Determinants of Economic Growth: A Cross-Country Empirical Study, NBER Working Paper No. 5968 (Cambridge, Massachusetts: National Bureau of Economic Research).

Barro, R. J. (2001). Human capital and growth. The American Economic Review, 91(2), 12-17.

Barro, R. J. \& Lee, J. W. (1993). International comparisons of educational attainment. Journal of monetary economics, 32(3), 363-394.

Belgrave, A. \& Craigwell, R. (1995). The Impact of government expenditure on economic growth in Barbados: A Disaggregated Approach. DeLisle Worrell and Roland Craigwell, 138.

Bergh, A. \& Fink, G. (2008). Higher Education Policy, Enrollment, and Income Inequality. Social Science Quarterly, 89(1).

Bloom, D. E., Canning, D., Chan, K. \& Luca, D. L. (2014). Higher education and economic growth in Africa. Higher Education and Economic Growth in Africa (December 18, 2014). International Journal of African Higher Education, 1(1).

Bloom, D. E., Canning, D. \& Chan, K. (2006). Higher education and economic development in Africa (Vol. 102): World Bank Washington, DC.

Chaudhary, A. R., Iqbal, A. \& Gillani, S. Y. M. (2009). The nexus between higher education and economic growth: An empirical investigation for Pakistan. Pakistan Journal of Commerce and Social Sciences, $3(1), 1-9$.

Chowdry, H., Crawford, C., Dearden, L., Goodman, A. \& Vignoles, A. (2008). Understanding the determinants of participation in higher education and the quality of institute attended: analysis using administrative data. Institute for Fiscal Studies, mimeo.

Clarke, P., Crawford, C., Steele, F. \& Vignoles, A. F. (2010). The choice between fixed and random effects models: some considerations for educational research. https://ideas.repec.org/p/iza/izadps/dp5287.html

Corazzini, A., Dugan, J., Dennis, J. \& Grabowski, H. G. (1972). Determinants and distributional aspects of enrollment in US higher education. Journal of Human Resources, 2, 39-59.

Fleischhauer, K. J. (2007). A Review of Human Capital Theory: Microeconomics, University of St. Gallen, Institute of Public Finance and Fiscal Law (IFF-HSG) Varnbüel strasse 19. Website http://www.iff.unisg.ch.

Fitzsimons, P. (1999). Human capital theory and education. Encyclopedia of Philosophy of Education Online.

Gemmell, N. (1996). Evaluating the impacts of human capital stocks and accumulation on economic growth: some new evidence. Oxford Bulletin of Economics and statistics, 58(1), 9-28.

Glewwe, P., Maiga, E. \& Zheng, H. (2007). The contribution of education to economic growth in Sub-Saharan Africa: A review of the evidence. Department of Applied Economics, University of Minnesota, 358, 559579.

Hanushek, E. A. \& Kimko, D. D. (2000). Schooling, labor-force quality, and the growth of nations. American economic review, 5, 1184-1208.

Hassan, S. \& Ahmed, H. (2008). Education's contribution to the economic growth of Sub-Saharan Africa. Southwestern Economic Review, 1(32), 175-190.

Holland, D., Liadze, I., Rienzo, C. \& Wilkinson, D. (2013). The relationship between graduates and economic growth across countries. BIS Research Paper, 110. 
Lucas, R. E. (1988). On the mechanics of economic development. Journal of monetary economics, 22(1), 3-42.

Mankiw, N. G., Romer, D. \& Weil, D. N. (1992). A contribution to the empirics of economic growth. The quarterly journal of economics, 107(2), 407-437.

Matsushita, S., Siddique, A. \& Giles, M. (2006). Education and economic growth: a case study of Australia: University of Western Australia, Economics.

McMahon, W. W. (2009). Higher learning, greater good: The private and social benefits of higher education: JHU Press.

Nnanna, O. J., Alade, S. O. \& Odoko, F. O. (2003). Contemporary economic policy issues in Nigeria: Central Bank of Nigeria.

Nurudeen, A. \& Usman, A. (2010). Government expenditure and economic growth in Nigeria, 1970-2008: A disaggregated analysis. Business and Economics Journal.

Okebukola, P. C. (2008). Education reform: Imperatives for achieving vision 20-2020. Paper Presented at the National Summit on Education, Organized by Senate Committee on Education, held at Sheraton Hotel. Abuja, December 10-11

Olawumi, O. S., Ogungbenle, S. \& Obasuyi, F. O. T. (2013). Life Expectancy, Public Health Spending and Economic Growth in Nigeria: A Vector Autoregressive (Var) Model. European Scientific Journal, 9, 1857 - 7881 (Print) e - ISSN 1857- 7431.

McMahon, W. W. (2009). Higher learning, greater good: The private and social benefits of higher education. JHU Press.

Romer, P. M. (1986). Increasing returns and long-run growth. Journal of political economy, 94(5), 1002-1037.

Shaihani, M., Harisb, A., Ismaila, N. \& Saida, R. (2011). Long run and short run effects on education levels: Case in Malaysia. International Journal of Economic Research, 2(6), 77-87.

Sojkin, B., Bartkowiak, P. \& Skuza, A. (2012). Determinants of higher education choices and student satisfaction: the case of Poland. HigherEducation, 63(5).

Tilak, J. B. G. (2005). Are we marching towards Laissez-faireism in higher education development? Journal of international cooperation in education, 8(1).

Tilak, J. B. G. (2011). Financing higher education in sub-saharan Africa. Africanus, 41(2), 4-31.

Verbic, M., Majcen, B. \& Cok, M. (2009). Education and Economic Growth in Slovenia: A Dynamic General Equilibrium Approach with Endogenous Growth.

World Bank. (2008). Acceleration Catch-up: Tertiary Education for Growth in Sub-Saharan Africa. World Bank, Washington D.C.

Zivengwa, T. (2006). Investigating the causal relationship between education and economic growth in Zimbabwe. Selim, 8. 